\title{
Attitude towards pre-implantation genetic diagnosis for hereditary cancer
}

\author{
Chantal Lammens · Eveline Bleiker · Neil Aaronson • Annette Vriends • \\ Margreet Ausems · Maaike Jansweijer · Anja Wagner · Rolf Sijmons · \\ Ans van den Ouweland · Rob van der Luijt · Liesbeth Spruijt • \\ Encarna Gómez García · Mariëlle Ruijs · Senno Verhoef
}

Published online: 30 July 2009

(C) The Author(s) 2009. This article is published with open access at Springerlink.com

\begin{abstract}
The use of pre-implantation genetic diagnosis (PGD) for hereditary cancer is subject to on-going debate, particularly among professionals. This study evaluates the attitude towards PGD and attitude-associated characteristics of those concerned: family members with a hereditary cancer predisposition. Forty-eight Von Hippel-Lindau and $18 \mathrm{Li}$-Fraumeni Syndrome families were identified via the 9 family cancer clinics in the Netherlands. In total, 216 high risk family members and partners were approached, of whom 179 (83\%) completed a self-report questionnaire. Of the high risk family members, $35 \%$ expressed a positive attitude towards PGD. Those with a current desire to have
\end{abstract}

\section{Lammens $\cdot$ N. Aaronson}

Division of Psychosocial Research \& Epidemiology, The

Netherlands Cancer Institute-Antoni van Leeuwenhoek Hospital

(NKI-AVL), Amsterdam, The Netherlands

\section{E. Bleiker}

Division of Psychosocial Research \& Epidemiology/Family

Cancer Clinic, The Netherlands Cancer Institute-Antoni van

Leeuwenhoek Hospital (NKI-AVL), Amsterdam, The

Netherlands

\section{A. Vriends}

Department of Human and Clinical Genetics, Leiden University

Medical Centre, Leiden, The Netherlands

M. Ausems · R. van der Luijt

Department of Medical Genetics, University Medical Centre

Utrecht, Utrecht, The Netherlands

M. Jansweijer

Department of Paediatric Genetics, Emma Children's Hospital/

Academic Medical Centre, Amsterdam, The Netherlands

A. Wagner · A. van den Ouweland

Department of Clinical Genetics, Erasmus Medical Centre,

Rotterdam, The Netherlands children were significantly more likely to have a positive attitude: $48 \%$ would consider the use of PGD. No other sociodemographic, medical or psychosocial variables were associated significantly with a positive attitude. The most frequently reported advantage of PGD is the avoidance of a possible pregnancy termination. Uncertainty about late effects was the most frequently reported disadvantage. These results indicate that approximately half of those contemplating a future pregnancy would consider the use of PGD. The actual uptake, however, is expected to be lower. There is no indication that psychosocial factors affect interest in PGD.

\section{R. Sijmons \\ Department of Genetics, University Medical Center Groningen, University of Groningen, Groningen, The Netherlands}

L. Spruijt

Department of Clinical Genetics, University Medical Centre Nijmegen, Nijmegen, The Netherlands

\section{E. Gómez García}

Department of Clinical Genetics, Academic Hospital Maastricht, Maastricht, The Netherlands

M. Ruijs

Department of Clinical Genetics, VU University Medical Centre, Amsterdam, The Netherlands

S. Verhoef $(\bowtie)$

Family Cancer Clinic, The Netherlands Cancer Institute-Antoni van Leeuwenhoek Hospital (NKI-AVL), Plesmanlaan 121,

1066 CX Amsterdam, The Netherlands

e-mail: s.verhoef@nki.nl 
Keywords Attitude $\cdot$ Hereditary cancer $\cdot$ Li-Fraumeni Syndrome (LFS) · Pre-implantation genetic diagnosis (PGD) · Von Hippel-Lindau disease (VHL)

\section{Introduction}

Family planning is one of the motives to undergo genetic testing for a hereditary cancer predisposition [1]. Family members at high risk are confronted with the actual possibility that they will transmit the cancer predisposition to their offspring. This can play an important role in reproductive decision-making.

Carriers of a hereditary cancer predisposition have up to six options with regard to reproductive decision making, namely: (1) to remain childless; (2) to have children and accept the $50 \%$ risk of their child inheriting the cancer predisposition; (3) to adopt a child; (4) to pursue gamete donation; (5) to undergo prenatal diagnosis (PND), with the possibility of pregnancy termination; or (6) to undergo preimplantation genetic diagnosis (PGD).

The last of these options, PGD, is a modern technique in reproductive medicine that involves in vitro fertilization (IVF) treatment followed by testing of 3-day old embryos for the familial genetic predisposition. Subsequently, only unaffected embryos are transferred to the uterus [2,3]. Although PGD has been performed for all major hereditary cancer syndromes [4], its use remains socially, ethically and politically controversial [5-9]. Recently, controversy about the use of PGD for hereditary cancer almost led to a cabinet crisis in the Netherlands [10]. One of the issues of debate concerned the circumstances under which the use of PGD is appropriate and acceptable. In particular, concern was expressed about a 'slippery slope' if PGD is to be used for susceptibilities (i.e., risks) rather than certainties.

The discussion about the use of PGD for hereditary cancer predispositions has been dominated by experts, including clinicians, geneticists, and ethicists. The lay perspective on PGD, and particularly that of members of families with a known hereditary cancer predisposition, is relatively unexplored. To date, four studies (one British and three American) have investigated family members' attitudes towards the use of PGD for hereditary cancer predispositions. In a small study $(N=20)$ of familial adenomatous polyposis (FAP), Kastrinos et al. [11] reported that all respondents were open to any form of prenatal testing for FAP-carriers, and that $90 \%$ of the respondents would personally consider the use of PGD. Menon et al. [12] found that $75 \%$ of a sample of BRCA gene mutation carriers $(N=52)$ considered it acceptable to offer PGD for hereditary breast and ovarian cancer (HBOC), and that $14 \%$ would personally consider its use. Recently, among 111 female conference attendees with either a personal or family history of breast and/or ovarian cancer, $57 \%$ believed that PGD is acceptable for BRCA 1/2 carriers; $33 \%$ would personally consider its use [13]. Finally, among 213 members of the advocacy group that organized the aforementioned conference, $13 \%$ indicated that they would consider the use of PGD [14].

In summary, these previous studies have reported relatively high levels of general acceptance of PGD for hereditary cancer, and a wide range of personal interest in its use (ranging from 13 to 90\%). However, all previous studies employed selective samples, almost all study participants were women, and none of the studies included spouses/partners. Additionally, in three studies sample sizes were relatively small and response rates were only moderate (ranging from 51 to 59\%) [11-13]. Finally, little information is available on the characteristics of individuals with a positive vs. negative attitude towards PGD. For example, are those who hold a positive attitude towards PGD more likely to have a personal history of cancer, to have high levels of cancer-related distress, or to have had highly negative experiences with the disease in their family?

The current study included a large sample of both male and female high-risk individuals from families with a known hereditary cancer predisposition, as well as their partners. In this study we focused on two hereditary cancer syndromes: Von Hippel-Lindau disease (VHL) and $\mathrm{Li}-$ Fraumeni Syndrome (LFS). VHL and LFS are both rare autosomal dominantly inherited tumor susceptibility syndromes, characterized by an increased risk of developing a broad spectrum of tumors. LFS is associated with germline mutations in the TP53 gene [15]; the causative mutation of VHL is a germline mutation in the VHL-gene [16]. LFS tumors are malignant and include soft-tissue sarcomas, osteosarcomas, early-onset breast cancer, acute leukemia, adrenocortical neoplasm's, central nervous system tumors, pancreatic cancer and Wilm's tumors [17-19]. Tumors occurring in VHL are both benign and malignant, including hemangioblastomas of the retina, cerebellum and spinal cord, pheochromocytomas, renal cysts, renal clear cell carcinomas and cysts and endocrine tumors of the pancreas $[20,21]$. VHL and LFS carriers have up to a $90 \%$ life-time risk of developing clinically relevant signs and symptoms. The age of onset of tumors varies widely (from early childhood to adulthood). There are no preventive treatment options available for VHL family members. The only preventive option for female LFS family members is prophylactic mastectomy to reduce the risk of breast cancer. In fact, for all VHL, and the majority of LFS affected individuals, treatment is available after clinical relevant expression of the disease only. In an effort to detect expression of the disease at an early stage, periodic screening is offered to high risk family members. 
The aim of our study was to investigate the attitudes of VHL and LFS family members towards PGD, and to identify characteristics associated significantly with a positive attitude towards its use.

\section{Materials and methods}

Study sample

This study is part of a large, nationwide, cross-sectional investigation of the psychosocial issues in VHL and LFS carried out in collaboration with the nine family cancer clinics in the Netherlands and the DNA-laboratories of the University Medical Centre Utrecht, the Erasmus Medical Centre, and the Netherlands Cancer Institute. Forty-three of the 48 families with a known VHL germline mutation and 15 of the 18 LFS families with a known p53 germline mutation were eligible for the study. Families were ineligible if no adult family members were still alive or residing in the Netherlands.

Questions on PGD were posed to the high risk family members (proven carriers, clinical diagnosis, individuals at $50 \%$ risk) 16 years of age or older, and to their partners. Individuals who were not aware that VHL or LFS runs in their family were excluded from the study. Family members were recruited between August 2006 and February 2008. The study was approved by the medical ethics committees of all participating hospitals.

\section{Procedure}

Eligible family members received a letter of invitation through their clinical geneticist, along with an information leaflet about the study, a consent form, a questionnaire and a prepaid return envelope. High risk family members who were not registered at a clinical genetics centre were invited through a registered family member. Consenting family members were asked to invite their partner to participate in the study. Adult carriers were also invited to include their children aged 16-18 years.

\section{Measures}

Study participants were asked to complete a self-report questionnaire including questions on sociodemographics, personal and family medical history, psychosocial variables, and attitude towards the use of pre-implantation genetic diagnosis.

\section{Dependent variable}

Attitude towards pre-implantation genetic diagnosis After a short introduction about PGD (see Textbox 1),

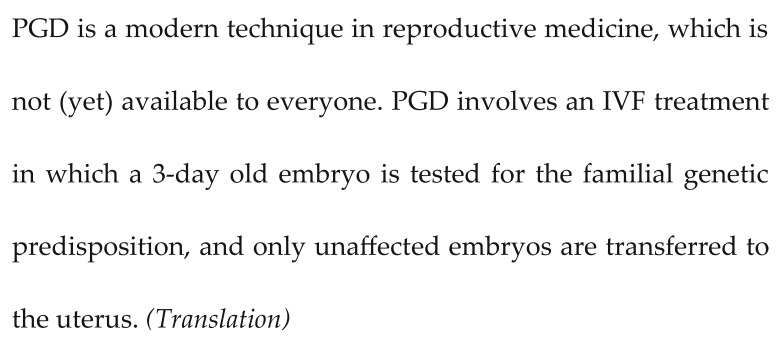

Textbox 1 Explanation of PGD towards study participants

respondents were asked the following question: "Would you consider the use of PGD if this would be/ would have been available to you?" (response categories: yes/no/ unsure). Additionally, respondents were asked to rate the advantages and disadvantages of PGD by ticking a list of five possible advantages and disadvantages.

Independent variables

Factors possibly related with an attitude towards the use of PGD were selected based on the literature and on clinical experience [22-24].

Sociodemographics and personal medical history Age, gender, marital status, educational level, religion, number of children and current desire to have children, and personal history of VHL or LFS were assessed via self-report.

Family history of VHL/LFS Participants were asked whether and, if so, how many close relatives (parents, siblings and children) were clinically and/or genetically diagnosed with VHL or LFS, and their age when they were first confronted with the VHL/LFS-related illness of a close family member. Parallel questions were posed regarding death of a family member related to VHL/LFS.

Psychosocial characteristics Cancer worries, perceived risk, feelings of guilt towards (future) children and syndrome-specific distress were assessed with standardized self-report questionnaires (see Table 1).

Statistical analysis

Descriptive statistics were generated regarding the attitudes of study participants towards PGD. Univariate analyses using chi-square, Fisher's exact test and Student's $t$-test were used to determine which sociodemographic, clinical and psychosocial variables are related significantly to the expressed attitude towards PGD. Initially, all analyses were carried out for the VHL and LFS subgroups separately. However, because attitudes toward PGD did not differ significantly as a function of hereditary cancer syndrome, the results are reported for the total sample. 


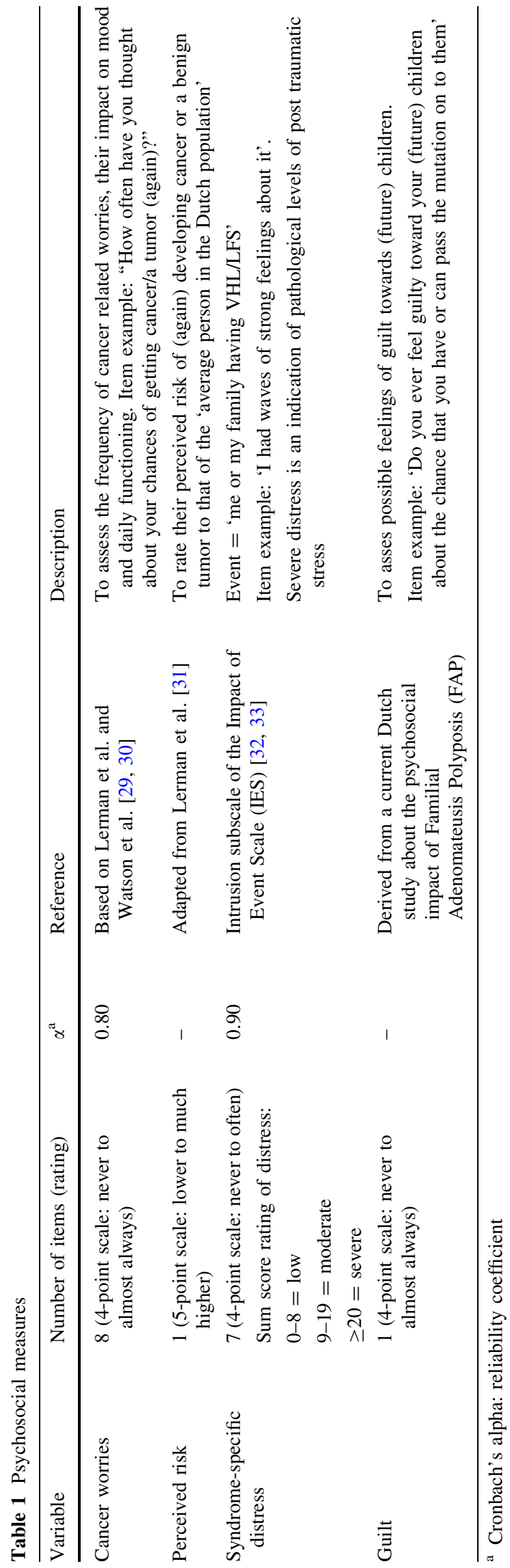

\section{Results}

Response

In total, 179 of the 216 invited individuals (83\%) from 9 LFS and 36 VHL families completed the questionnaire, including 95 (a)symptomatic carriers, 34 family members at $50 \%$ risk and 50 partners. There were no statistically significant differences between respondents and nonrespondents in sociodemographic or clinical background variables.

Sample characteristics

Characteristics of the study sample are shown in Table 2. Approximately two-thirds of the respondents were VHL family members, and one-third LFS family members. The respondents' age ranged between 16 and 75 years (mean = 39.9 years; $S D=14.0$ years $)$. Gender and percentage in the childbearing age range (aged 40 or younger) were equally distributed. The majority of the sample indicated a religious affiliation, with Catholicism being the most prevalent religion $(34 \%)$.

Family members' attitudes towards PGD

None of the participants had used PGD. Thirty-five percent of the $129 \mathrm{VHL} / \mathrm{LFS}$ family members indicated that they would consider the use of PGD if this would be/would have been a possibility for them, $27 \%$ was uncertain, and $38 \%$ would not use PGD.

As can be seen in Table 3, a current desire to have children was related significantly to a positive attitude towards PGD, with those with such plans being more likely to express an intention to use PGD than those without such plans (48 vs. $25 \%$, respectively; $P=0.01)$. Individuals within the childbearing age range tended to have a more positive attitude towards PGD than those over 40 years of age (41 vs. $26 \%$, respectively; $P=0.10$ ), as did those without vs. with children (43 vs. 29\%, respectively; $P=0.09$ ). None of the medical (e.g., personal history of VHL/LFS, number of affected first degree relatives) or psychosocial variables (e.g., cancer worries, syndrome-related distress, feelings of guilt towards (future) children) were associated significantly with attitude towards PGD.

Partners' attitudes toward PGD

Of the 50 partners, one-third would consider the use of PGD if this would be/would have been a possibility for them, $11(22 \%)$ were not sure, and $22(45 \%)$ would not use PGD. None of the sociodemographic or medical variables 
Table 2 Characteristics of respondents $(N=179)$

\begin{tabular}{|c|c|}
\hline & $N(\%)$ \\
\hline \multicolumn{2}{|l|}{ Syndrome } \\
\hline Li-Fraumeni Syndrome (LFS) & $62(35)$ \\
\hline Von Hippel-Lindau disease (VHL) & $117(65)$ \\
\hline \multicolumn{2}{|l|}{ Personal VHL/LFS status } \\
\hline Carriers & $95(53)$ \\
\hline $50 \%$ at-risk & $34(19)$ \\
\hline Partners & $50(28)$ \\
\hline Age $($ mean $\pm \mathrm{SD})$ & $39.9 \pm 14.0$ \\
\hline \multicolumn{2}{|l|}{ Childbearing age } \\
\hline Yes $(\leq 40)$ & $89(50)$ \\
\hline No $(>40)$ & $90(50)$ \\
\hline \multicolumn{2}{|l|}{ Gender } \\
\hline Male & $91(51)$ \\
\hline Female & $88(49)$ \\
\hline \multicolumn{2}{|l|}{ Marital status } \\
\hline Married/living together & $140(79)$ \\
\hline Single & $38(21)$ \\
\hline Missing & 1 \\
\hline Children (Yes) & $103(58)$ \\
\hline \multicolumn{2}{|l|}{ Educational level } \\
\hline Low & $44(25)$ \\
\hline Moderate & $93(52)$ \\
\hline High & $42(23)$ \\
\hline \multicolumn{2}{|l|}{ Religion } \\
\hline Protestant & $19(11)$ \\
\hline Dutch reformed (Calvinist) & $15(8)$ \\
\hline Catholic & $61(34)$ \\
\hline Other & $27(15)$ \\
\hline None & $57(32)$ \\
\hline
\end{tabular}

were associated significantly with attitudes toward PGD, although male partners tended to be more positive than female partners (44 vs. $21 \%$, respectively; $P=0.08$ ). Consistent with the high risk family members, none of the psychosocial variables were significantly associated with a positive attitude towards PGD.

\section{Ratings of advantages and disadvantages of PGD}

As shown in Table 4, the most frequently rated perceived advantage of PGD was avoiding the possibility of a selective pregnancy termination (32\%). The most frequently rated disadvantage of PGD was the fact that the long-term effects of PGD are unknown (18\%). It should be noted, however, that nearly half of the family members and partners did not endorse any of the possible advantages of PGD, and slightly more than two-thirds did not endorse any of the possible disadvantages of PGD.

\section{Discussion}

To our knowledge, this is the first large scale investigation of the attitudes towards the use of PGD and attitudeassociated characteristics of patients, partners and at high risk members from families with a known hereditary cancer predisposition for Von Hippel-Lindau disease or $\mathrm{Li}-$ Fraumeni Syndrome. Approximately one-third of the family members and their partners expressed a positive attitude towards the use of PGD. Those family members with a current desire to have children were significantly more likely to have such a positive attitude. Approximately half of the family members and partners contemplating a future pregnancy would, based on their current knowledge, consider the use of PGD. No other sociodemographic, medical or psychosocial variables were associated significantly with a positive attitude towards PGD.

Concern has been expressed that the availability of PGD for cancer susceptibilities could, in time, result in a significant increase in the number of PGD requests for a growing number of diseases which, by objective standards, might be perceived to be less severe; the so called 'slippery slope' argument. A 10 year evaluation from the single, certified PGD centre in the Netherlands found that, following an informational intake session and/or the provision of written materials, $44 \%$ of individuals declined the use of PGD [25] (reasons for decline e.g.: (a) invasive procedure (b) low success rate personal communication de Die \& Geraedts, single PGD centre the Netherlands). Therefore, although half of those with a current desire to have children would consider the use of PGD, in practice only a subset will eventually opt for PGD. In the past it has also been observed in requests for prenatal diagnosis (PND) that the actual uptake was lower than the expected requests. For example, Adams et al. [22] reported that $18 \%$ of Huntington disease carriers used PND, while based on earlier survey data $65 \%$ was expected to do so. In previous studies of high risk HBOC en FAP family members, of those contemplating a future pregnancy, $14 \%$ (1:7) to $100 \%$ (9:9) indicated that they would consider the use of PGD [11-13]. However, the sample sizes in these studies were too small to draw firm conclusions on the personal acceptability of PGD for these hereditary cancer predispositions. Based on our study results, and on the available literature, it is not expected that making PGD available to members of hereditary cancer families will result in a very large uptake of the procedure. A more significant uptake of PGD may be expected when success rates of PGD increase and when the possible long-term health risks for the newborns have been demonstrated to be negligible.

The majority of participants in our study did not endorse any specific advantages or disadvantages of PGD. This may have been due to limited knowledge about PGD. The 
Table 3 Attitude of high risk family members towards pre-implantation genetic diagnosis $(N=119)$

\begin{tabular}{|c|c|c|c|}
\hline & $\begin{array}{l}\text { Would use } \\
\text { PGD } N(\%)\end{array}$ & $\begin{array}{l}\text { Would not } \\
\text { use or unsure } \\
\text { about using } \\
\text { PGD } N(\%)\end{array}$ & $P$-value \\
\hline Total & $41(35)$ & $78(65)$ & \\
\hline \multicolumn{4}{|l|}{ Sociodemographics } \\
\hline \multicolumn{4}{|l|}{ Gender } \\
\hline Male & $22(36)$ & $39(64)$ & .70 \\
\hline Female & $19(33)$ & $39(67)$ & \\
\hline \multicolumn{4}{|l|}{ Education } \\
\hline Low & $8(27)$ & $22(73)$ & .27 \\
\hline Moderate & $20(33)$ & $41(67)$ & \\
\hline High & $13(46)$ & $15(54)$ & \\
\hline Age $($ mean $\pm \mathrm{SD})$ & $36.7(12.6)$ & $39.4(14.2)$ & .31 \\
\hline \multicolumn{4}{|l|}{ Childbearing age } \\
\hline Yes $(\leq 40$ years $)$ & $27(41)$ & $39(59)$ & .10 \\
\hline No ( $>40$ years) & $14(26)$ & $39(74)$ & \\
\hline \multicolumn{4}{|l|}{ Children } \\
\hline Yes & $18(28)$ & $47(72)$ & .09 \\
\hline No & $23(43)$ & $31(57)$ & \\
\hline \multicolumn{4}{|c|}{ Current desire to have children } \\
\hline Yes/maybe & $23(48)$ & $25(52)$ & .01 \\
\hline No & $18(25)$ & $53(75)$ & \\
\hline \multicolumn{4}{|l|}{ Religion } \\
\hline Protestant & $5(45)$ & $6(55)$ & \\
\hline Dutch reformed & $1(10)$ & $9(90)$ & \\
\hline Catholic & $18(39)$ & $28(61)$ & .45 \\
\hline Other & $6(32)$ & $13(68)$ & \\
\hline None & $11(33)$ & $22(67)$ & \\
\hline \multicolumn{4}{|l|}{ Medical } \\
\hline \multicolumn{4}{|l|}{ Syndrome } \\
\hline Von Hippel-Lindau & $26(33)$ & $53(67)$ & 62 \\
\hline Li-Fraumeni Syndrome & $15(38)$ & $25(62)$ & \\
\hline \multicolumn{4}{|l|}{ DNA status } \\
\hline (a)symptomatic carrier & $31(34)$ & $59(66)$ & .99 \\
\hline At $50 \%$ risk & $10(35)$ & $19(65)$ & \\
\hline \multicolumn{4}{|c|}{ Personal history of VHL/LFS } \\
\hline Yes & $26(37)$ & $44(63)$ & .46 \\
\hline No & $15(31)$ & $34(69)$ & \\
\hline \multicolumn{4}{|c|}{ Affected first degree relative ${ }^{\mathrm{a}}$} \\
\hline None & $9(43)$ & $12(57)$ & .34 \\
\hline $\begin{array}{l}\text { During childhood } \\
\text { ( }<13 \text { years })\end{array}$ & $18(39)$ & $28(61)$ & \\
\hline $\begin{array}{l}\text { During adolescence } \\
\quad(13-20 \text { years })\end{array}$ & $6(35)$ & $11(65)$ & \\
\hline $\begin{array}{l}\text { During adulthood } \\
\quad(>20 \text { years })\end{array}$ & $7(22)$ & $25(78)$ & \\
\hline 3 missing cases & - & - & \\
\hline
\end{tabular}

Table 3 continued

\begin{tabular}{|c|c|c|c|}
\hline & $\begin{array}{l}\text { Would use } \\
\text { PGD } N(\%)\end{array}$ & $\begin{array}{l}\text { Would not } \\
\text { use or unsure } \\
\text { about using } \\
\text { PGD } N(\%)\end{array}$ & $P$-value \\
\hline \multicolumn{4}{|c|}{ Number of affected first degree relatives } \\
\hline None & $4(57)$ & $3(43)$ & \\
\hline $1-2$ & $16(35)$ & $30(65)$ & .28 \\
\hline 3 or more & $15(28)$ & $38(72)$ & \\
\hline 5 missing cases & - & - & \\
\hline \multicolumn{4}{|l|}{ Death first degree relative ${ }^{a}$} \\
\hline None & $22(39)$ & $34(61)$ & .45 \\
\hline $\begin{array}{l}\text { During childhood } \\
\text { ( }<13 \text { years })\end{array}$ & $5(28)$ & $13(72)$ & \\
\hline $\begin{array}{l}\text { During adolescence } \\
\quad(13-20 \text { years })\end{array}$ & $7(44)$ & $9(56)$ & \\
\hline $\begin{array}{l}\text { During adulthood } \\
\quad(>20 \text { years })\end{array}$ & $7(25)$ & $21(75)$ & \\
\hline 1 missing case & - & - & \\
\hline \multicolumn{4}{|c|}{ Number deceased first degree relatives } \\
\hline None & $22(41)$ & $32(59)$ & \\
\hline $1-2$ & $14(29)$ & $35(71)$ & .42 \\
\hline 3 or more & $4(33)$ & $8(67)$ & \\
\hline 4 missing cases & - & - & \\
\hline \multicolumn{4}{|l|}{ Psychosocial } \\
\hline Cancer worries (mean $\pm \mathrm{SD}$ ) & $14.7 \pm 4.5$ & $14.2 \pm 4.9$ & .57 \\
\hline \multicolumn{4}{|l|}{ IES-intrusion (mean (sd)) } \\
\hline Low & $27(35)$ & $51(65)$ & .80 \\
\hline Moderate & $9(31)$ & $20(69)$ & \\
\hline High & $5(42)$ & $7(58)$ & \\
\hline \multicolumn{4}{|c|}{ Risk perception of developing a tumor } \\
\hline Low & $6(25)$ & $18(75)$ & \\
\hline Moderate & $19(42)$ & $26(58)$ & .34 \\
\hline High & $16(33)$ & $32(67)$ & \\
\hline \multicolumn{4}{|l|}{ Guilt towards (future) children } \\
\hline Never/Sometimes & $29(36)$ & $52(64)$ & .55 \\
\hline Often/almost always & $11(42)$ & $15(58)$ & \\
\hline
\end{tabular}

Partners in separate analyses; 10 missing cases

${ }^{a}$ Developmental phase of participant when they first experienced the diagnosis or death of a first degree relative

number of participants who were familiar with PGD prior to participating in the current study is unknown. An earlier study in the Netherlands of individuals with other hereditary conditions for which the use of PGD is permitted, reported that approximately half of respondents was unfamiliar with PGD [26]. Similarly, Quinn et al. [13] reported that the majority of the high risk HBOC conference attendees were unaware of PGD before they participated in the study. Similar percentages may be expected for 
Table 4 Rated advantages and disadvantages PGD $(N=179)$

\begin{tabular}{lr}
\hline & $\%$ \\
\hline Advantages & 47 \\
Participant did not endorse any of the advantages & 32 \\
Avoiding the possibility of a pregnancy termination & 12 \\
Avoiding the birth of a(nother) child with VHL/LFS & 9 \\
Reduces chance on miscarriage & 6 \\
No advantages & 68 \\
Disadvantages & 18 \\
Participant did not endorse any of the disadvantages & 10 \\
Long term effects unknown & 10 \\
low success rate & 8 \\
Chance of wrong diagnosis & \\
Expensive &
\end{tabular}

members from families with other known hereditary cancer predispositions. Although we described the technique of PGD (see Textbox 1), the information might have been too limited for some respondents to form an opinion. Those who expressed an opinion rated the avoidance of a possible selective pregnancy termination as the most important advantage. In a study by Lavery et al. [27] among carriers of Cystic Fibrosis, X-linked disorders and chromosomal disorder who underwent PGD, this was the primary factor motivating individuals to opt for PGD. The most frequent rated disadvantage was the fact that long term effects of the procedure are as yet unknown.

In our opinion, clinical geneticists and counselors should carefully consider informing individuals undergoing genetic counseling for serious hereditary cancer syndromes about the available reproductive options, including PGD. Ultimately, as recommended by the European Society for Human Reproduction \& Embryology (ESHRE) and the European Society for Human Genetics (ESHG), it may be advisable to make reproductive options equally available and accessible throughout Europe [28].

Informing counselees about PGD can be done via written educational materials, but preferably should also be combined, where appropriate, with counseling by a clinical geneticist. For example, information leaflets about the possible reproductive options could be provided at the time of clinical diagnosis or genetic testing to individuals with a current or future desire to have children. Advantages as well as disadvantages of each option could be outlined, and counselees could be actively encouraged to contact their counselor for more detailed information. Increased awareness of reproductive options, including PGD, might also reduce the number of 'silent sufferers' who chose not to have children because of fear of transmitting the predisposition to their offspring. Based on the results of our study, there is no indication that psychosocial factors, such as cancer worries or cancer-related distress, are associated significantly with interest in undergoing PGD. Rather, it is the simple desire to have children that motivates such interest. Nevertheless, we would recommend monitoring the effect of undergoing PGD on individuals' psychosocial health and well-being.

Acknowledgments We are grateful to all of the respondents who participated in the study, and we thank Tanja Nagtegaal and Miranda Gerritsma (NKI-AVL, Amsterdam) for their important contribution to the data collection. Furthermore we would like to thank Kirsten Douma for her intellectual input in designing the questionnaire; and Dr. Christine de Die and Professor Dr. Joep Geraedts for their information on motives for declining PGD.

Funding This study was financially supported by the Dutch Cancer Society (grant number 2005-3209).

Open Access This article is distributed under the terms of the Creative Commons Attribution Noncommercial License which permits any noncommercial use, distribution, and reproduction in any medium, provided the original author(s) and source are credited.

\section{References}

1. Pasacreta JV (2003) Psychosocial issues associated with genetic testing for breast and ovarian cancer risk: an integrative review. Cancer Invest 21:588-623. doi:10.1081/CNV-120022380

2. Handyside AH, Kontogianni EH, Hardy K et al (1990) Pregnancies from biopsied human preimplantation embryos sexed by Y-specific DNA amplification. Nature 344:768-770. doi:10.1038/ $344768 \mathrm{a} 0$

3. Sermon K, Van Steirteghem A, Liebaers I (2004) Preimplantation genetic diagnosis. Lancet 363:1633-1641. doi:10.1016/S01406736(04)16209-0

4. Offit K, Kohut K, Clagett B et al (2006) Cancer genetic testing and assisted reproduction. J Clin Oncol 24:4775-4782. doi:10.1200/ JCO.2006.06.6100

5. (2006) Ethics of preimplantations genetic diagnosis for cancer. Lancet Oncol 7:611. doi:10.1016/S1470-2045(06)70768-9

6. Harris M, Winship I, Spriggs M (2005) Controversies and ethical issues in cancer-genetics clinics. Lancet Oncol 6:301-310. doi: 10.1016/S1470-2045(05)70166-2

7. Niermeijer MF, De Wert GM, Dondorp W (2006) Preimplantation genetic diagnosis for cancer. Lancet Oncol 7:794. doi:10.1016/ S1470-2045(06)70876-2

8. Niermeijer MF, Die-Smulders CE, Page-Christiaens GC et al (2008) [Genetic cancer syndromes and reproductive choice: dialogue between parents and politicians on preimplantation genetic diagnosis] Erfelijke kankersyndromen en kinderwens: ouders en politiek in dialoog over pre-implantatiegenetische diagnostiek. Ned Tijdschr Geneeskd 152:1503-1506

9. Robertson JA (2003) Extending preimplantation genetic diagnosis: the ethical debate. Ethical issues in new uses of preimplantation genetic diagnosis. Hum Reprod 18:465-471. doi:10.1093/hum rep/deg 100

10. Sheldon T (2008) Netherlands debates screening for breast cancer. BMJ 336:1270. doi:10.1136/bmj.39598.672500.DB

11. Kastrinos F, Stoffel EM, Balmana J et al (2007) Attitudes toward prenatal genetic testing in patients with familial adenomatous polyposis. Am J Gastroenterol 102:1284-1290. doi:10.1111/ j.1572-0241.2007.01168.x 
12. Menon U, Harper J, Sharma A et al (2007) Views of BRCA gene mutation carriers on preimplantation genetic diagnosis as a reproductive option for hereditary breast and ovarian cancer. Hum Reprod 22:1573-1577. doi:10.1093/humrep/dem055

13. Quinn G, Vadaparampil S, Wilson C et al (2008) Attitudes of high-risk women toward preimplantation genetic diagnosis. Fertil Steril 91:2361-2368

14. Staton AD, Kurian AW, Cobb K et al (2008) Cancer risk reduction and reproductive concerns in female BRCA1/2 mutation carriers. Fam Cancer 7:179-186. doi:10.1007/s10689-0079171-7

15. Malkin D, Li FP, Strong LC et al (1990) Germ line p53 mutations in a familial syndrome of breast cancer, sarcomas, and other neoplasms. Science 250:1233-1238. doi:10.1126/science.1978757

16. Linehan WM, Lerman MI, Zbar B (1995) Identification of the von Hippel-Lindau (VHL) gene. Its role in renal cancer. JAMA 273:564-570. doi:10.1001/jama.273.7.564

17. Birch JM, Alston RD, McNally RJ et al (2001) Relative frequency and morphology of cancers in carriers of germline TP53 mutations. Oncogene 20:4621-4628. doi:10.1038/sj.onc.1204621

18. Kleihues P, Schauble B, zur Hausen A et al (1997) Tumors associated with p53 germline mutations: a synopsis of 91 families. Am J Pathol 150:1-13

19. Nichols KE, Malkin D, Garber JE et al (2001) Germ-line p53 mutations predispose to a wide spectrum of early-onset cancers. Cancer Epidemiol Biomarkers Prev 10:83-87

20. Lonser RR, Glenn GM, Walther M et al (2003) von HippelLindau disease. Lancet 361:2059-2067. doi:10.1016/S0140-6736 (03)13643-4

21. Maher ER, Yates JR, Harries R et al (1990) Clinical features and natural history of von Hippel-Lindau disease. Q J Med 77:11511163

22. Adam S, Wiggins S, Whyte P et al (1993) Five year study of prenatal testing for Huntington's disease: demand, attitudes, and psychological assessment. J Med Genet 30:549-556. doi:10.1136/ jmg.30.7.549

23. Decruyenaere M, Evers-Kiebooms G, Boogaerts A et al (2007) The complexity of reproductive decision-making in asymptomatic carriers of the Huntington mutation. Eur J Hum Genet 15:453-462. doi:10.1038/sj.ejhg.5201774
24. Farhi D, Bastuji-Garin S, Khosrotehrani K et al (2008) Neurofibromatosis 1: analysis of the demand for prenatal diagnosis in a French cohort of 361 patients. Am J Med Genet A 146:159-165. doi:10.1002/ajmg.a.32066

25. Die-Smulders CE, Land JA, Dreesen JC et al (2004) Results from 10 years of preimplantation-genetic diagnostics in The Netherlands. Ned Tijdschr Geneeskd 148:2491-2496

26. Musters AM, Oosterwijk C, Repping S et al (2008) Doelgroep is onwetend: onbekendheid met pre-implantatie genetische diagnostiek is groot. Med Contact (Bussum) 63:980-983

27. Lavery SA, Aurell R, Turner C et al (2002) Preimplantation genetic diagnosis: patients' experiences and attitudes. Hum Reprod 17:2464-2467. doi:10.1093/humrep/17.9.2464

28. Kääriäinen $H$ (2006) The need for interaction between assisted reproduction technology and genetics. Recommendations of the European societies of human genetics and human reproduction and embryology. Eur J Hum Genet 14:509-511. doi:10.1038/ sj.ejhg. 5201600

29. Lerman C, Kash K, Stefanek M (1994) Younger women at increased risk for breast cancer: perceived risk, psychological well-being, and surveillance behavior. Monogr Natl Cancer Inst 16:171-176

30. Watson M, Duvivier V, Wade Walsh M et al (1998) Family history of breast cancer: what do women understand and recall about their genetic risk? J Med Genet 35:731-738. doi:10.1136/jmg.35.9.731

31. Lerman C, Seay J, Balshem A et al (1995) Interest in genetic testing among first-degree relatives of breast cancer patients. Am J Med Genet 57:385-392. doi:10.1002/ajmg.1320570304

32. Horowitz MJ (1982) Stress response syndromes and their treatment. In: Goldberger L, Breznitz S (eds) Handbook of stress: theoretical and clinical aspects. Collier Macmillan Publishers, London, pp 711-732

33. Brom D, Kleber RJ (1985) De schok verwerkingslijst. Ned Tijdschr Psychol 40:164-168. Impact of event scale 